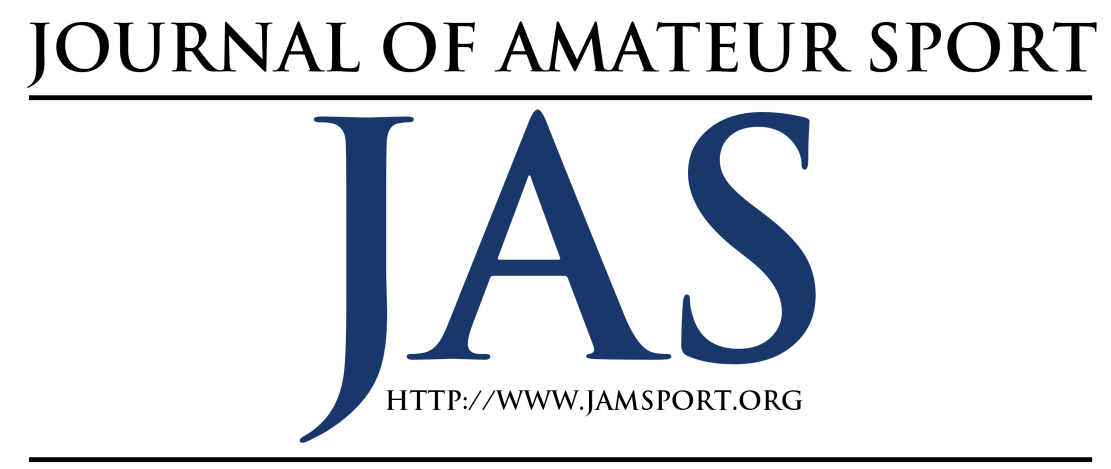

\title{
Exploring the Relationship Between the Relative Age Effect and Youth Development Among Male Recreational Ice Hockey Players
}

\author{
Laura Chittle \\ Patti Weir
}

\author{
Sean Horton \\ Jess Charles Dixon
}

\section{University of Windsor}

The current study examined if relative age influences the youth developmental experiences of male recreational ice hockey players. Participants completed an online survey that solicited their date of birth and responses to the Youth Experience Survey for Sport (YES-S). Our analysis revealed no relative age effect among the recreational hockey players. The MANOVA results revealed no significant multivariate differences between quartile of birth and the five YES-S dimensions ( $p$ $=.493)$. It is reassuring that the experiences of the recreational ice hockey players in our sample do not differ in their developmental experiences as a consequence of when they were born throughout the selection year.

$\mathrm{P}$ articipation in organized extracurricular activities has been associated with various positive outcomes including increased academic achievement (Cooper, Valentine, Nye, \& Lindsay, 1999), interpersonal competence (Mahoney, Cairns, \& Famer, 2003), college attendance (Mahoney et al., 2003; Zaff et al., 2003), civic involvement (Zaff et al., 2003), and lower rates of early school dropout (Mahoney \& Cairns, 1997). Organized sport has become a popular activity for youth, particularly in Canada, where approximately $76 \%$ of Canadians aged 6-17 years were found to participate in at least one form of organized sport (Guèvremont, Findlay, \& Kohen, 2008). Youth sport is recognized as an excellent opportunity for children to improve their physical health skills, as well as their psychosocial development (e.g., cooperation, discipline, leadership) and motor skills (Côté \& Fraser-Thomas, 2007). 
While sport offers many benefits, it can also lead to negative outcomes including injuries (Merkel, 2013), increased alcohol consumption (Eccles \& Barber, 1999) and parental pressure, as well as poor relationships with coaches (Fraser-Thomas \& Côté, 2009). Taken together, sport is a domain that furnishes participants with a wide range of both positive and negative experiences, highlighting the importance and need to ensure that sporting environments are organized and structured effectively to foster positive development (MacDonald, Côté, Eys, \& Deakin, 2012).

There are many underlying factors (e.g., coaching, motivational climate, peers) that may influence the experience youth have within sport, one of which is relative age. Relative age can be described as the age differences among individuals in the same cohort (Barnsley, Thompson, \& Barnsley, 1985). To illustrate this point, an 11-month age disparity among 10 -year-old children represents nearly $10 \%$ of total life experience (Musch \& Grondin, 2001). Further, relative age can interact with various primary (i.e., training, genetic, and psychological factors) and secondary factors (i.e., socio-cultural and contextual factors) that can influence skill acquisition (Baker \& Horton, 2004). Unfortunate, yet common, consequences of relative age differences are relative age effects (RAEs). These are (dis)advantages one experiences as a result of his or her birthdate relative to a predetermined cut-off date (Barnsley et al., 1985). When using a January $1^{\text {st }}$ cut-off date, an individual born in January is almost a whole year older than someone born in December. This disparity can help precipitate the various mechanisms (i.e., physiological development, psychological maturity, experience, competition) (Musch \& Grondin, 2001) behind the formation of RAEs. A traditional RAE occurs when there are a greater proportion of relatively older individuals participating in an activity whose birthdates fall shortly after a cut-off date compared to their relatively younger peers.

Within educational literature, relative age has been found to influence academic performance (Cobley, Baker, Wattie, \& McKenna, 2009a), the diagnosis of Attention Deficit Hyperactivity Disorder (ADHD; Elder, 2010), leadership roles (Dhuey \& Lipscomb, 2008), and attendance at a post-secondary school (Bedard \& Dhuey, 2006). Specifically, those who are relatively younger tend to have lower grades, are more likely misdiagnosed with ADHD, less frequently hold a leadership position (e.g., club president), and are less likely to attend a post-secondary institution. Such disadvantages extend beyond education into other domains, including sport. Relative age effects have been found to exist in a number of sports (e.g., soccer, hockey, baseball, and basketball) and at various levels of competition (Cobley, Baker, Wattie, \& McKenna, 2009b). Because relatively younger athletes tend to be physically smaller, this can lead to them being overlooked by coaches and less likely to be identified as talented at an early age 
(Helsen, Starkes, \& Winckel, 1998).

Alternatively, those who are relatively older are more commonly considered to be talented and, consequently, are exposed to better coaching (Helsen et al., 1998), as well as achieve greater success (Barnsley et al., 1985), ultimately leading to a more positive and enjoyable sporting experience. Relative age effects within sport can negatively impact the experiences of those who are relatively younger and can lead to these athletes dropping out (Barnsley \& Thompson, 1988; Delorme, Boiche, \& Raspaud, 2010; Helsen et al., 1998; Lemez, Baker, Horton, Wattie, \& Weir, 2014). Helsen et al. (1998) noted that relatively younger male soccer players tended to drop out as early as 12 years of age.

To date, there have been a variety of proposed solutions to eliminate or minimize RAEs. However, many of these seem to be administratively challenging or have failed to garner the attention of sport governing bodies. Some solutions include grouping athletes based on height and weight (e.g., Musch \& Grondin, 2001), alternating cutoff dates from year to year (e.g., Barnsley \& Thompson, 1988), implementing age quota systems (e.g., Barnsley \& Thompson, 1988), or delaying the selection process and representation of athletes (i.e., streaming) (Baker, Schorer, \& Cobley, 2010). Given that these proposed solutions have yet to receive traction from sport governing bodies, it is imperative to continue evaluating the experiences youth have during sport. Despite what researchers know about the presence of RAEs within sport, there has been a void in the literature examining the role relative age may have on the personal development of youth within these activities. To this point, the purpose of the current study is to examine if relative age influences youth developmental experiences as measured by the Youth Experience Survey for Sport (YES-S; MacDonald et al., 2012). The YES-S was created from a modified version of the Youth Experience Survey 2.0 (YES; Hansen $\&$ Larson, 2005) to measure the positive and negative personal developmental experiences of youth in sport.

\section{Literature Review}

\section{RAEs in Hockey}

Canadian ice hockey and volleyball were the first sports found to be influenced by RAEs. An unequal birth distribution was found for Canadian ice hockey players as well as male and female volleyball players participating at recreational, competitive, and senior professional levels (Grondin, Deschaies, \& Nault, 1984). Shortly thereafter, Barnsley et al. (1985) provided strong evidence of a linear relationship between month of birth and participation rates in the National Hockey League (NHL), Ontario Hockey League, and Western Hockey League. Since these foundational studies, ice hockey has become a primary focus for RAE studies. Specifically, Cobley et al. (2009b) identified through their meta-analysis that $32.8 \%$ of RAE studies focused on ice hockey. At the 
NHL level, numerous studies have confirmed the presence of RAEs (Addona \& Yates, 2010; Barnsley et al., 1985; Boucher \& Mutimer, 1994; Côté, MacDonald, Baker, \& Abernethy, 2006; Montelpare, Scott, \& Pelino, 2000; Nolan \& Howell, 2010). Wattie, Baker, Cobley, and Montelpare (2007) examined the history of the NHL and concluded that the RAE emerged within the late 1970s. Similarly, Addona and Yates (2010) found evidence that the RAE began for NHL players born since 1951. The authors concluded this birthdate bias was a result of the Soviet Union's rise as a dominant force in international hockey, which resulted in Canada changing its national development programs.

Relative age effects have been found to exist in other elite levels of hockey, including Canadian intercollegiate athletics (Chittle, Horton, \& Dixon, 2015; Montelpare et al., 2000), the Canadian Hockey League (Nolan \& Howell, 2010), and within four countries (i.e., Canada, United States, Sweden, and Finland) participating in the International Ice Hockey Federation's World Junior Hockey Championships (Bruner, Macdonald, Pickett, \& Côté, 2011). Likewise, Baker and Logan (2007) provided evidence that hockey players born in the first half of the year were more likely to be selected in the 2000-2005 NHL entry drafts; however, relatively younger Canadian hockey players appeared to be selected earlier in the draft. While relatively younger athletes are often seen as disadvantaged within the literature, research has suggested that relatively younger NHL players are more likely selected as All-Stars and to participate on Olympic teams, as well as have longer careers (Gibbs, Jarvis, \& Dufur, 2011). Furthermore, Wattie, Cobley, et al. (2007) found relatively older children participating in ice hockey were more often injured than their relatively younger peers.

A likely contributing factor to the RAEs witnessed in elite hockey stem from similar birthdate distributions seen in youth leagues. Within the Edmonton Minor Hockey Association, traditional RAEs were found in the 'Pee Wee,' 'Bantam,' 'Midget,' and 'Juvenile' leagues (Barnsley \& Thompson, 1988). Further, the authors demonstrated a significant relationship between birth quartile and youth participation, where those who were relatively older tended to participate on top tier teams. As a result, these players are more likely to be selected to the professional ranks. Similarly, relative age advantages were witnessed in a sample of select players participating in the Calgary Minor Hockey Association, whereby more than $60 \%$ of players were born in the first half of the year (Montelpare et al., 2000). Hancock, Ste-Marie, and Young (2013) also found strong evidence of a RAE for males registered in the Ontario Hockey Federation (OHF) who were participating competitively (i.e., where coaches selected players). The aforementioned studies highlight the 
importance of competition to the development of RAEs within youth hockey.

Typically, when examining youth hockey at the house league level there are no RAE trends. House league hockey can be defined " ... as a community oriented Minor hockey program structured to provide development and competition at the recreational level" (Hockey Canada, 2013, p. 57). For example, Montelpare et al., (2000) found nearly an equal birthdate distribution for their sample of house league players, where $53 \%$ were born in the first half of the year and $47 \%$ in the second half. In contrast, Hancock et al. (2013) found significant RAE trends for the noncompetitive (i.e., where no coach selection was made) divisions of 'Initiation' and 'Novice' for players registered in the OHF. While the older divisions demonstrated birthdate distributions that were significantly different from what would be expected in the general population, they were not consistent with a traditional RAE pattern. Nevertheless, players who were relatively older were consistently underrepresented within these older divisions.

\section{Positive/Negative Youth Development}

Research by MacDonald, Côté, Eys, and Deakin (2011) examined the various factors that influence positive and negative personal development for male and female athletes and found affiliation with peers, selfreferenced competence, effort expenditure, and task climate were all significant predictors of positive sport experiences.

Conversely, ego climate and otherreferenced competency were predictors of negative experiences. Creating an environment that is athlete-focused, and encourages goal setting and sharing may help build stronger relationships among peers and increase motivation, (MacDonald et al., 2011). Moreover, Fraser-Thomas et al. (2011) examined sport program characteristics (e.g., sport type, training time, team sex) to determine their role in youths' developmental experiences. Key findings included age as a predictor of initiative and cognitive skills, whereby those who are older had more experiences in initiative and cognitive skills. Additionally, the results suggested that co-ed teams scored higher in the area of personal and social skills, and players coached by the same sex scored higher in the initiative domain. Other research has found coach autonomy support to be associated with personal and social skills, cognitive skills, goal setting, and initiative (Cronin \& Allen, 2015). Research conducted on adolescent soccer players found that team success had no correlation with the overall developmental experience; however, coach transformational leadership behavior and the coach-athlete relationship appeared to be the best predictors of athletes' positive developmental experiences such as goal setting, initiative, and personal and social skills (Vella, Oades, \& Crowe, 2013).

With obesity rates in children rising (Janssen et al., 2005), it is of the utmost 
importance to ensure youth continue to participate in extracurricular activities such as sport. Regular physical activity is an effective method to prevent chronic diseases such as obesity (Warburton, Nicol, $\&$ Bredin, 2006). As a result, the aim of this study is to answer the following research question: does relative age influence youth developmental experiences within male house league hockey? Within the 2013-2014 hockey season 138,768 males were participating at the 'Bantam' and 'Midget' level (Hockey Canada, 2014), providing a large number of individuals available to survey. More importantly, this division is often viewed as both competitive, yet popular among youth since skill level is not a criterion for participation. By comparing the sport experiences relatively younger and older athletes have, respectively, we may be in a better position to guide decisionmaking when creating new sport programs or modifying existing ones. Finally, to the best of our knowledge this is the first study to examine the influence of relative age on the five dimensions of the YES-S.

\section{Methods}

\section{Youth Experience Survey for Sport}

The YES-S is a 37-item instrument that examines five dimensions of youth development including: personal and social skills, initiative, goal setting, cognitive skills, and negative experiences (MacDonald et al., 2012). The personal and social skills dimension consists of 14 items (e.g., 'I became better at giving feedback'). The initiative dimension is comprised of four items (e.g., 'I learned to push myself). The goal setting dimension contains four items (e.g., 'I learned to find ways to reach my goals'). The cognitive skills dimension consists of five items (e.g., 'I improved skills for finding information'). Finally, the negative experiences dimension is made up of ten items (e.g., 'I was treated differently because of my gender, race, ethnicity, disability, or sexual orientation'). The items on the YES-S are rated on a 4point Likert scale ranging from 1 (Not at all) to 4 (Yes definitely) that represents experiences that occurred during sport participation. The YES-S has been established to have adequate model fit and reliability with 9-19-year-old youth sport participants (MacDonald et al., 2012).

\section{Sample}

For this research, 464 male house league ice hockey players completed an online survey hosted by Fluidsurveys. These players were sampled from one of three hockey tournaments that took place within the Canadian province of Ontario in 2014. Participants answered a variety of demographic questions including date of birth and completed the YES-S (MacDonald et al., 2012). Prior to completing the online survey participants were asked to read the online consent form and check a box indicating that they consent to participate in this research project and acknowledge the risks involved. 


\section{Procedure \& Data Analysis}

The sample was delimited $(n=453)$ to include only to those who answered a minimum of 30 out of the 37 items (i.e., $80 \%$ ) on the YES-S, provided complete responses to the remaining portions of the survey (e.g., date of birth), and to correct for various forms of response bias. Participants ranged from 15 to 21 years of age, with nearly $92 \%$ of athletes 16 through 18 years old. Since most of our sample is between 16-18 years of age, and beyond the age at which maturation variability is at its peak among adolescent males (Musch \& Grondin, 2001), we believe our results are less likely to be influenced by the potential physiological and cognitive differences associated with age disparities. Thus, we can more effectively isolate the influence of relative age on these individuals. Case mean substitution was used to deal with the remaining missing data (El-Masri \& FoxWasylyshyn, 2005), which is appropriate when $20 \%$ (or less) of the items are missing (Downey \& King, 1998). Once data were collected, mean scores for each YES-S dimension were calculated for each participant. These scores were then used to compare how the positive and negative developmental experiences in sport differed among participants and test for the influence of relative age on these scores.

To determine if there was a RAE present within this sample, athletes were grouped into the appropriate birth quartile using December $31^{\text {st }}$ as the cut-off date (Hockey Canada, 2013). Those born in the months of January, February, and March were placed in quartile one (Q1), quartile two (Q2) consisted of those born in April, May and June, quartile three (Q3) represented those born in July, August, and September, and quartile four (Q4) included those born in October, November, and December. A chi-square goodness of fit test $\left(X^{2}\right)$ was performed to determine if the observed birthdate distribution of these male house league ice hockey players differed significantly from what we would expect to see based on OHF birthdates for midget players ages 15-17 (Hancock et al., 2013). Effect sizes were calculated using Cramér's phi $(\varphi)$. Based on previous research involving recreational hockey players, we did not expect to find a RAE (e.g., Barnsley \& Thompson, 1988; Montelpare et al., 2000). Finally, a multivariate analysis of variance (MANOVA) was conducted to compare the scores of the various sub-scales of the YES$S$ across birth quartiles. Through these analyses we attempted to discern how relative age may be influencing the positive and negative sporting experiences of youth ice hockey players. This research project has received ethical review and clearance, consistent with the guidelines set out in the Canadian Tri-Council Policy Statement for Research Involving Humans (2010).

\section{Results}

Within our sample, 102 athletes were born in Q1 (22.5\%), $128(28.3 \%)$ in Q2, 118 $(26.0 \%)$ in Q3, and $105(23.2 \%)$ in Q4. The 
results of the chi-square goodness of fit test revealed no significant differences between the birthdate distribution of our sample of house league hockey players and what we would expect among players in the $\mathrm{OHF}$ $\left(X^{2}=3.762, d f=3, p=.288, \varphi=0.091\right.$, see Figure 1). As a result, we conclude there is no RAE within this sample.

Cronbach's (1951) alpha $(\alpha)$ scores were computed to measure the internal consistency of the dimensional subscales, and all were deemed acceptable (i.e., scores greater than .70; George \& Mallery, 2003). The MANOVA revealed no significant multivariate differences between quartile of birth and the five YES-S dimensions (Pillai's Trace $=.032, \mathrm{~F}(15,1,341)=.963, \mathrm{p}=.493)$. Therefore, it appears that the experiences of the house league ice hockey players in our sample do not differ in their developmental experiences as a consequence of when they were born throughout the selection year. As per the recommendation of an anonymous reviewer, we reanalyzed our data using years of hockey experience as a covariate and found similar results.

Based on the relative ages of the participants, scores on the YES-S range from 3.31-3.37 for personal and social skills, 2.49-2.70 for cognitive skills, 3.20-3.25 for goal setting, 3.55-3.61 for initiative, and 1.56-1.71 for negative experiences. See Table 1 for details regarding the mean and standard deviation of the YES-S sub-scales based on quartile of birth.

\section{Discussion}

To our knowledge, this is the first study to examine the relationship between relative age and youth experiences in sport. The results of this study support similar findings that male house league ice hockey players are not disadvantaged as a result of their date of birth (e.g., Hancock et al., 2013; Montelpare et al., 2000). Thus, the potential benefits (or detriments) relative age has on these players is essentially nonexistent. Since house league hockey players often compete at this level for enjoyment reasons, rather than in pursuit of a professional career, it is reassuring that they are not having disparate experiences as a result of their relative ages. Despite the null findings in this study, we believe relative age ought to be considered in other studies exploring positive youth development within sport to provide a more comprehensive analysis of other potential influences on youth sporting experiences. This may be particularly true when examining the development of youth competing at higher levels of competition, where the RAE is more prominent.

There is growing emphasis on the importance of publishing null findings (Ioannidis, 2005, 2006), as they save fellow researchers both time and resources examining phenomena that may fail to exist. Furthermore, Ioannidis (2006) goes so far as to suggest that journals should always publish null results, providing they recognize their limitations, and only publish significant findings after replica studies have been conducted. With this in mind, it is 
important to highlight the limitations associated with the current study. Firstly, the participants within this study were recruited at hockey tournaments throughout Ontario and thus, likely reside in the province of Ontario. As a result, caution should be used when generalizing these results to other regions across Canada. Also, as with any self-reported survey instrument, it is difficult to ensure participants answered questions about their youth experiences in sport thoughtfully and honestly.

Furthermore, we recommend replicating this study with samples drawn from other competitive levels (e.g., AAA) to determine if experiences in sport would differ across quartiles at more elite levels of competition. Future research of this nature conducted on female athletes, in different geographic regions, as well as in different sports would be beneficial and insightful.

The scores of the participants in this study on personal and social skills, goal setting, and initiative resemble those of Cronin and Allen's (2015) study where participants rated themselves above 3.00 for personal and social skills, goal setting, and initiative, but only 2.11 for cognitive skills. These authors stress the role that coaches have in youth development and well-being. Specifically, Cronin and Allen suggest that coaches should develop an autonomysupportive climate (e.g., listening to athletes) and provide opportunities for youth to develop positively through various actions (e.g., teaching goal setting, controlling emotions). The hockey players' self-rated scores for negative experiences (1.56-1.71) in this study are nearly identical to the average ratings (1.71) presented by MacDonald et al. (2011). Scores reported for the cognitive (2.26), goal setting (3.06), and initiative (3.47) subscale ratings are also similar to our sample (cognitive skills: 2.492.70; goal setting: 3.20-3.25; initiative: 3.553.61). As a result, the house league hockey players in our sample seem to be enjoying the psychosocial benefits that youth sport has to offer.

It is a positive sign that youth within our sample are both experiencing the positive and (to a lesser degree) negative outcomes of sport, regardless of their relative ages. However, it is important to acknowledge that those who may have had negative sporting experiences have potentially already dropped out. This is noteworthy given that other investigations have noted relatively younger athletes dropping out of sport due to their negative experiences (e.g., Barnsley \& Thompson, 1988; Helsen et al., 1998; Lemez et al., 2014). Outside of sport, relatively older high school students have been found to hold leadership roles more often and obtain more leadership experience prior to graduation (Dhuey \& Lipscomb, 2008). In light of the current findings and the similar results of Chittle, Horton, Weir, and Dixon (2015) it appears that relatively younger and older hockey players demonstrate similar leadership behaviors, possibly due to their participation in house league sport. If sport provides opportunities that are transferrable 
to other life contexts, the impact of relative age may diminish.

Given that sport participation is an excellent means to maintain health, and develop psychosocial and motor skills (Côté \& Fraser-Thomas, 2007), it is of the utmost importance that sport developers continue exploring all factors that can influence these experiences. Furthermore, participation in extracurricular activities has been shown to improve academic achievement (Cooper et al., 1999) and extend to other areas such as college attendance (Mahoney et al., 2003), and civic involvement (Zaff et al., 2003). In the future, parents, teachers, and other relevant stakeholders should consider promoting sport to children, particularly at the house league level, as a method to facilitate positive development (i.e., goal setting, personal and social skills, cognitive skills, and initiative) and leadership skills, given that relative age plays no discriminating role in these outcomes. Using sport as an avenue to foster personal growth has the potential to shape and influence other areas of development, including education and career opportunities. 


\section{References}

Addona, V., \& Yates, P. A. (2010). A closer look at the relative age effect in the National Hockey League. Journal of Quantitative Analysis in Sports, 6(4), doi:10.2202/1559-0410.1227.

Baker, J., \& Horton, S. (2004). A review of primary and secondary influences on sport expertise. High Ability Studies, 15(2), 211-228.

Baker, J., \& Logan, A. J. (2007).

Developmental contexts and sporting success: Birth date and birthplace effects in National Hockey League draftees 2000-2005. British Journal of Sports Medicine, 41(8), 515-517. doi:10.1136/bjsm.2006.033977.

Baker, J., Schorer, J., \& Cobley, S. (2010). Relative age effects. Sportwissenschaft, 40(1), 26-30.

Barnsley, R. H., \& Thompson, A. H. (1988). Birthdate and success in minor hockey: The key to the NHL. Canadian Journal of Behavioural Science, 20, 167-176.

Barnsley, R. H., Thompson, A. H., \& Barnsley, P. E. (1985). Hockey success and birthdate: The RAE. Canadian Association for Health, Physical Education, and Recreation, 51, 23-28.

Bedard, K., \& Dhuey, E. (2006). The persistence of early childhood maturity: International evidence of long-run age effects. The Quarterly Journal of Economics, 121(4), 14371474.
Boucher, J. L. \& Mutimer, B. T. (1994). The relative age phenomenon in sport: A replication and extensions with icehockey players. Research Quarterly for Exercise and Sport, 65(4), 377-381.

Bruner, M. W., Macdonald, D. J., Pickett, W., \& Côté, J. (2011). Examination of birthplace and birthdate in world junior ice hockey players. Journal of Sport Sciences, 29(12), 1337-1344.

Canadian Institutes of Health Research, Natural Sciences and Engineering Research Council of Canada, and Social Sciences and Humanities Research Council of Canada (2010). Tri-Council Policy Statement: Ethical Conduct for Research Involving Humans. Retrieved from http://www.pre.ethics.gc.ca/pdf/eng /tcps2/TCPS_2_FINAL_Web.pdf

Chittle, L., Horton, S., \& Dixon, J. C. (2015). Exploring the relative age effect in Canadian interuniversity ice hockey. Talent Development \& Excellence, 7(1), 69-81.

Chittle, L., Horton, S., Weir, P., \& Dixon, J. C. (2015). Investigating the relationship between the relative age effect and leadership behaviors among male ice hockey players. International Review for the Sociology of Sport. doi: 10.1177/1012690215616271

Cobley, S., Baker, J., Wattie, N., \& McKenna, J. M. (2009a). How pervasive are relative age effects in secondary school education? Journal of 
Educational Psychology, 101(2), 520-

528.

Cobley, S., Baker, J., Wattie, N., \&

McKenna, J. M. (2009b). Annual agegrouping and athlete development: A meta-analytic review of relative age effects in sport. Sports Medicine, 39(3), 235-256.

Cooper, H., Valentine, J. C., Nye, B., \& Lindsay, J. J. (1999). Relationships between five afterschool activities and academic achievement. Journal of Educational Psychology, 91(2), 369-78.

Côté, J., \& Fraser-Thomas, J. (2007). Youth involvement in sport. In P. R. E. Crocker (Ed.), Introduction to sport psychology: A Canadian perspective (pp. 266-294). Toronto: Pearson Prentice Hall.

Côté, J., MacDonald, D. J., Baker, J., \& Abernethy, B. (2006). When 'where' is more important than 'when': Birthplace and birthdate effects on the achievement of sporting expertise. Journal Sports Science, 24(10), 1065-1073.

Cronbach, L. J. (1951). Coefficient alpha and the internal structure of tests. Psychometric, 16, 297-334.

Cronin, L. D., \& Allen, J. B. (2015).

Developmental experiences and wellbeing in sport: The importance of the coaching climate. The Sport Psychologist, 29, 62-71.

Delorme, N., Boiché, J., \& Raspaud, M. (2010). Relative age effect in female sport: A diachronic examination of soccer players. Scandinavian Journal of Medicine and Science in Sports, 20, 509515.

Dhuey, E., \& Lipscomb, S. (2008). What makes a leader? Relative age and high school leadership. Economics of Education Review, 27, 173-183.

Downey, R. G., \& King, C. V. (1998). Missing data in Likert ratings: Comparison of replacement methods. The Journal of General Psychology, 125(2), 175-191.

Eccles, J. S., \& Barber, B. L. (1999). Student council, volunteering, basketball, or marching band: What kind of extracurricular involvement matters? Journal of Adolescent Research, 14, 10-43.

Elder, T. (2010). The importance of relative standards in ADHD diagnoses: Evidence based on exact birth dates. Journal of Health Economics, 29, 641656.

El-Masri, M., \& Fox-Wasylyshyn, S. (2005). Missing data: An introductory overview for the novice researcher. Canadian Journal of Nursing Research, 37(4). 156-171.

Fraser-Thomas, J., \& Côté, J., \& (2009). Understanding adolescents' positive and negative developmental experiences in sport. The Sport

Psychologist, 23, 3-23.

Fraser-Thomas, J., Côté, J., Holt, N., Beesley, T., MacDonald, D., Tamminen, K. (2011, October). Assessing youth sport programs' facilitation of positive youth 
development. Paper presented at Sport Canada Research Initiative Conference, Ottawa, Ontario.

Abstract retrieved from http://sirc.ca/sites/default/files/con tent/docs/Document/en_fraserthomas_jessica.pdf

George, D., \& Mallery, P. (2003). SPSS for Windows step by step: A simple guide and reference. 11.0 update (4th ed.). Boston: Allyn \& Bacon.

Gibbs, B. G., Jarvis, J. A., \& Durfur, M. J. (2011). The rise of the underdog? The relative age effect reversal among Canadian-born NHL hockey players: A reply to Nolan and Howell. International Review for the Sociology of Sport, 47(5), 644-649.

Grondin, S., Deschaies, P., \& Nault, L. P. (1984). Trimestres de naissance et participation au hockey et au volleyball. La Revue Québecoise de l'Activité Physique, 2, 97-103.

Guèvremont, A., Findlay, L., \& Kohen, D. (2008). Organized extracurricular activities of Canadian children and youth. Health Reports, 19, Statistics Canada, Catalogue no. 82-003-XPE.

Hancock, D. J., Ste-Marie, D. M., \& Young, B. W. (2013). Coach selections and the relative age effect in male youth ice hockey. Research Quarterly for Exercise and Sport, 84, 126-130.

Hansen, D.M., \& Larson, R. (2005). The Youth Experience Survey 2.0: Instrument revisions and validity testing. Unpublished manuscript, University of Illinois, Urbana-Champaign, Illinois.

Helsen, W. F., Starkes, J. L., \& Van Winckel, J. (1998). The influence of relative age on success and dropout in male soccer players. American Journal of Human Biology, 10, 791-798.

Hockey Canada. (2014). 2014 annual report. Retrieved from http://cdn.agilitycms.com/hockeycanada/Corporate/About/Downloa ds /2014_dec_annual_report_e.pdf

Hockey Canada (2013). Articles by-laws regulations history. Retrieved from http://assets.ngin.com/attachments/ document/0044/0627/2013_14_artic les_bylaws_e.pdf

Ioannidis, J. P. (2005). Why most published research findings are false. PLoS Medicine, 2(8), e124.

Ioannidis, J. P. (2006). Journals should publish all "null" results and should sparingly publish "positive" results. Cancer Epidemiology, Biomarkers \& Prevention, 15(1), 186.

Janssen, I., Katzmarzyk, P. T., Boyce, W. F., Vereecken, C., Mulvihill, C., Roberts, C., . . Picket, W. (2005). Comparison of overweight and obesity prevalence in school-aged youth from 34 countries and their relationships with physical activity and dietary patterns. Obesity Reviews, 6, 123-132.

Lemez, S., Baker, J., Horton, S., Wattie, N., \& Weir, P. (2014). Examining the relationship between relative age, competition level, and dropout rates 
in male youth ice-hockey players. Scandinavian Journal of Medicine \& Science in Sports, 24, 935-942, doi:10.1111/sms.12127.

MacDonald, D. J., Côté, J., Eys, M., \& Deakin, J. (2012). Psychometric properties of the youth experience survey with young athletes. Psychology of Sport \& Exercise, 13, 332-340.

MacDonald, D. J., Côté, J., Eys, M., \& Deakin, J. (2011). The role of enjoyment and motivational climate in relation to the personal development of team sport athletes. The Sport Psychologist, 25, 32-46.

Mahoney, J. L., \& Cairns, R. B. (1997). Do extracurricular activities protect against early school dropout? Developmental Psychology, 33(2), 241253.

Mahoney, J., Cairns, B., \& Famer, T. (2003). Promoting interpersonal competence and educational success through extracurricular activity participation. Journal of Educational Psychology, 5(2), 409-418.

Merkel, D. L. (2013). Youth sport: Positive and negative impact on young athletes. Journal of Sports Medicine, 4, 151-160.

Montelpare, W. J., Scott, D., \& Pelino, M. (2000). Tracking the relative age effect across minor, amateur and professional ice-hockey leagues. In A. B. Ashare (Ed.), Safety in ice hockey (vol. 3, pp. 250-260). Philadelphia,
PA: American Society for Testing and Materials.

Musch, J., \& Grondin, S. (2001). Unequal competition as an impediment to personal development: A review of the relative age effect in sport. Developmental Review, 21, 147-167.

Nolan, J. E., \& Howell, G. (2010). Hockey success and birth date: The relative age effect revisited. International Review for the Sociology of Sport, 45(4), 507-512. Vella, S. A., Oades, L. G., \& Crowe, T. P. (2013). The relationship between coach leadership, the coach-athlete relationship, team success, and the positive developmental experiences of adolescent soccer players. Physical Education and Sport Pedagogy, 18(5), 549-561.

Warburton, D. E., Nicol, C. W., \& Bredin, S. S. (2006). Health benefits of physical activity: the evidence. Canadian Medical Association Journal, 174(6), 801-809.

Wattie, N., Baker, J., Cobley, S., \& Montelpare, W. J. (2007). A historical examination of relative age effects in Canadian hockey players. International Journal of Sport Psychology, 38(2), 178186.

Wattie, N., Cobley, S., Macpherson, A., Howard, A., Montelpare, W. J., \& Baker, J. (2007). Injuries in Canadian youth ice hockey: The influence of relative age. Pediatrics, 120(1), 142 148. doi: 10.1542/peds.2006-2672. 
Zaff, J. F., Moore, K. A., Papillo, A., Williams, S. (2003). Implications of extracurricular activity participation on positive outcomes. Journal of Adolescent Research, 18(6), 599-630. doi: $10.1177 / 0743558403254779$. 


\section{Tables and Figures}

Table 1

Means and standard deviations for the Youth Experience Survey for Sport (YES-S) based on quartile of birth

\begin{tabular}{lcccc}
\hline YES-S subscales & $\begin{array}{c}\text { Q1 } \\
\text { Mean(SD) }\end{array}$ & $\begin{array}{c}\text { Q2 } \\
\text { Mean(SD) }\end{array}$ & $\begin{array}{c}\text { Q3 } \\
\text { Mean(SD) }\end{array}$ & $\begin{array}{c}\text { Q4 } \\
\text { Mean(SD) }\end{array}$ \\
\hline Personal and social skills & $3.31(.49)$ & $3.37(.47)$ & $3.32(.45)$ & $3.31(.45)$ \\
Cognitive skills & $2.64(.82)$ & $2.70(.78)$ & $2.51(.78)$ & $2.49(.75)$ \\
Goal Setting & $3.22(.69)$ & $3.25(.65)$ & $3.24(.61)$ & $3.20(.60)$ \\
Initiative & $3.59(.54)$ & $3.61(.52)$ & $3.61(.43)$ & $3.55(.47)$ \\
Negative experiences & $1.56(.56)$ & $1.71(.68)$ & $1.60(.61)$ & $1.67(.62)$
\end{tabular}

Note: Q1 = Quartile one; Q2 = Quartile two; Q3 = Quartile three; Q4 = Quartile four. Scores are based on a 4-point Likert scale ancored from 1 (Not at all) to 4 (Yes definitely). 
Figure 1

Overall birth distribution by quartile. Expected average population birth rates for males were derived from those who were registered in the Ontario Hockey Federation in 2007 (Hancock et al., 2013).

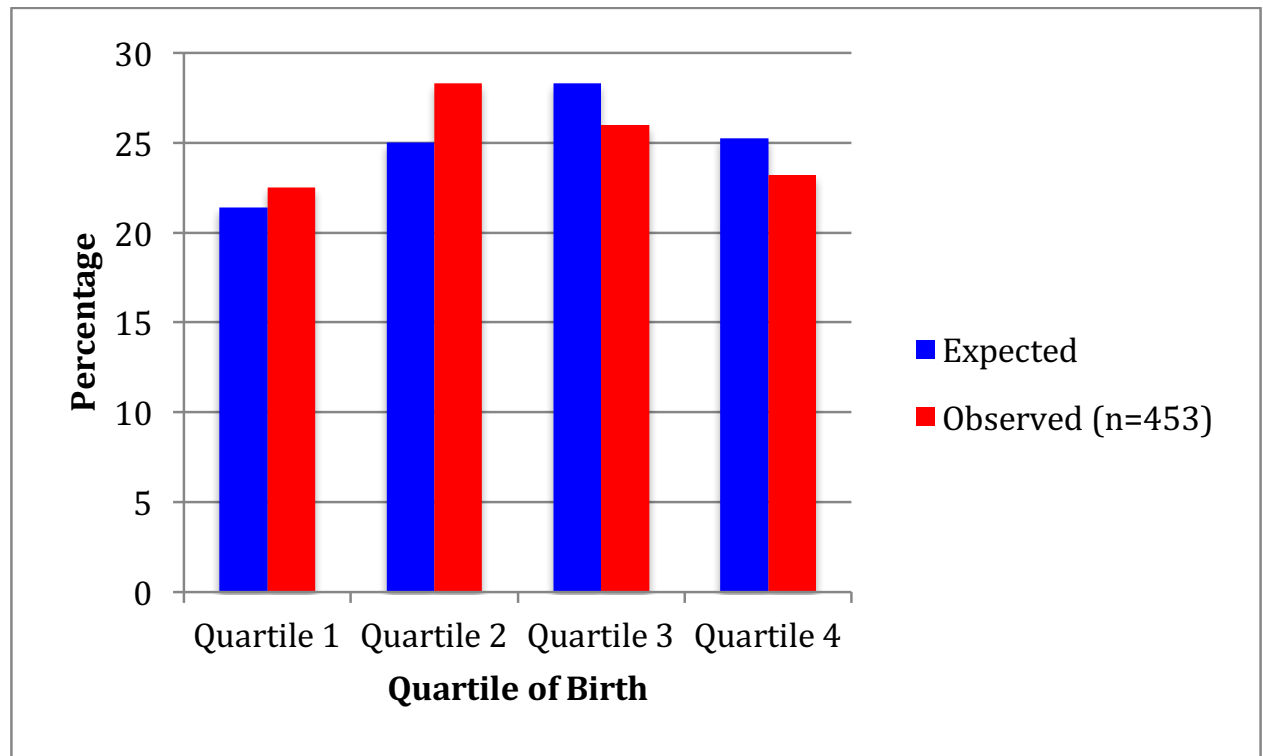

